Theories \& Applications, the International Edition

Printed Version: (ISSN 2090-5262)

Online Version: (ISSN 2090-5270)

November 2012, Volume 2, No. 3 Pages (104 - 116)

\title{
Effects of the Commercial Energy Drink (Red Bull) on College Students Athletic Performance and Anthropometric Variables
}

\author{
Kazem Jaber Ghloum*, Salman Hussein Mohammad**
}

\begin{abstract}
:
There is a worldwide problem with consumption of energy drinks especially with college students. Many researchers have suggested the negative side effects that go along with high consumption of these drinks especially ones that contain caffeine. The high rate consuming energy drinks (Red Bull) among college students may lead to many health problems. The initial purpose of this study was to determine the pattern of consumption of commercial energy drinks among Kuwaiti college students. Based on the results of the questionnaire, the effects of the caffeinated energy drink (Red Bull) on aerobic performance, anaerobic performance and body composition of college students were further investigated. A self-administered survey was collected from 84 students randomly selected from Department of Physical Education and Sports to assess the consumption patterns and knowledge of energy drinks. Awareness of college students of the ingredients and potential health hazards of energy drinks (Red Bull) should be emphasized in the college curriculum through nutritional and health education classes. Although we reported improvement in anaerobic performance, Red Bull should not be used for this purpose.
\end{abstract}

\section{Introduction:}

$\mathrm{E}$ nergy drinks were first introduced in 1987 and since then, their growth worldwide has been enormous. Energy drink consumption has continued to gain popularity since it was introduced in Austria in 1987 and also in the United States in 1997. Since then, the energy beverage market has grown exponentially. Most energy drinks are carbonated drinks that contain large amounts of caffeine which is often combined with sugar, B vitamins, amino acids (e.g. taurine), and herbal stimulants such as Guarana to form what manufacturers have called an "energy blend" (16). For example, Taurine appears to play an important role in muscle contraction (especially in the heart) and the nervous system and other ingredients $(11,12)$.

Although the US Food and Drug Administration

* Associate Professor, Department of Physical Education and Sport, College of Basic Education, The Public Authority for Applied Education and Training, The State of Kuwait.

** Assistant Professor, Department of Physical Education and Sport, College of Basic Education, The Public Authority for Applied Education and Training, The State of Kuwait.
(FDA) has set a limit on the caffeine content of soft drinks (68 mg per 12 ounces), energy drinks are not regulated at this point and some contain up to $500 \mathrm{mg}$ of caffeine $(10,16)$. Hundreds of different brands are now marketed with caffeine contents ranging from a modest $50 \mathrm{mg}$ (fixx ${ }^{\mathrm{TM}}$ ) to an alarming $505 \mathrm{mg}$ (Wired $\times 505^{\mathrm{TM}}$ ) per can or bottle. Caffeine, the most physiologically active ingredient in energy drinks, is generally considered safe by the (FDA) although adverse effects can occur at varying amounts. Caffeine, a central nervous system and cardiac stimulant, is the most popular and most readily available drug in the world $(28,51)$. Red Bull, the current leader in the energy drink marketing in Kuwait as well as in other countries, has been the energy drink of choice among of the college students. Unfortunately, there is no regulation for usage of Red Bull in Kuwait. For this reason, Red Bull is available in all supermarkets and many vending machines located at the university campus and private health clubs.

It is also should be mentioned that many stores and supermarkets display energy drinks next to the sport drinks. The consumers (students) and general population can assume that they are 
similar products. A differentiation should be distinguished between sport drinks and energy beverages. Sport drinks such as Gatorade and PowerAde, have been used to assist athletes performance through hydration and replenishment of electrolytes and carbohydrates during exercise and by providing carbohydrates (sugar). Sugar provides the working skeletal muscle with necessary glucose and electrolytes that help in the chemical reactions that provide energy. In contrast, energy drinks that contain high amounts of caffeine ranging from $80 \mathrm{mg}$ to $505 \mathrm{mg} / \mathrm{can}$ act as a diuretic and promote dehydration. Most energy drinks also contain sugar in an amount that exceeds the maximum recommended daily amount (15).

It well established that caffeine consumption can produce anxiety, nervousness, restlessness, insomnia and increased blood pressure (10). Excess caffeine intake has been shown to result in headaches, nausea, and all symptoms related to dehydration. In addition, can lead to hydration and weight gain which may have negative effects on a students' future health.

RResearch has shown the effects of caffeine to be inconsistent and several studies have reported that energy drinks such as Red Bull are being consumed pre-exercise by both recreational and the athletic population. They also reported no beneficial effects of the anaerobic or aerobic abilities $(1,2,3,4)$. Other studies reported an improved physical performance after consuming caffeine $(5,6,9,13)$.

In addition, the results of the self-administered questionnaire in the present study showed that a high percentage of Kuwaiti college students consume Red Bull daily and $91.7 \%$ believed that Red Bull increases physical fitness.

Therefore, the purpose of the present study is to increase the physical education department students awareness and knowledge regarding the consumption of energy drinks especially those most available in Kuwait (Red Bull). Also, the authors attempt to investigate the effects of $160 \mathrm{mg}$ caffeine (2 Red Bull cans) consumption on student athletic performance and body composition. An aerobic endurance test $(1600 \mathrm{~m})$ and anaerobic power test (Wingate) were administered to determine the physiological performance effects. In addition,
BMI and BOD POD methods were used to determine anthropometric variables.

\section{Methods:}

A self-administered questionnaire was used to determine Red Bull consumption patterns and general knowledge of sports/soft drinks in 84 out of $285(29.5 \%)$ randomly selected students from the Department of Physical Education and Sport attending the College of Basic Education in Public Authority of Applied Education and Training in The State of Kuwait. Among the 84 participates, only 14 reported consuming 1 or 2 cans per week $(29.8 \%)$. These subjects were selected and further investigated to compare the effects of consuming 2 Red Bull cans in anaerobic power and aerobic endurance performance. These subjects are athletes whom representing different sporting clubs in the State of Kuwait.

All subjects answered the questions which were collected by the researchers after completion. The anonymous questionnaire collected information was based on personal and demographic information (name, age, weight and height). To assure that selected subjects will be contacted for further investigation, cell phone numbers were obtained and recorded. The following questions were a screening process used to identify energy drink users. The questions focused on frequency patterns, average number of energy drinks consumed per week and the brand name. The students' knowledge regarding the amount of caffeine in the individual can, side effects associated with the drink used and if they read the cans content labels were also questioned. The following questions aimed to clarify the reasons for using the drink if to increase physical performance, awakeners or concentration. Finally, questions regarding if the drink helped their physical performance, mental alertness, increase the heart pulse and cause dizziness were asked.

Based on the results of the questionnaire, the authors selected all the subjects who consumed Red Bull drinks daily (14 students) from a total of 84 students who consumed Red Bull non daily to further measure their anthropometric (body composition). To determine the subjects' anthropometric variables, two measures were 
taken at the beginning of the first semester (September 2011) and at the end of the same semester (December 2011), a period of three months. All measurements for body composition were taken in the morning and testing procedures were performed in the afternoon at the physical education track and field and exercise physiology lab. Since the subjects are department students, the authors have control on the mode of communications and test arrangements. They were asked to continue their training and daily consumption of the energy drinks. Several lectures were given regarding diet intake prior to the day of testing. The subjects also asked to refrain from any strenuous physical activity prior to the testing.

\section{Body Composition Assessments:}

All subjects reported to the lab in the morning and the measurements were taken before the first class after fasting for eight hours and restrained from any physical activities.

To calculate body composition, the body weight (weight gain/loss), two estimations by two methods were used in this investigation. First, body weight index (BMI) was used to determine weight relative to height and obesity related health risks. Height was measured on stadiometer (Leicester, England) to the nearest $0.1 \mathrm{~cm}$, and the weight was recorded on a portable scale (model 707, Seca Corporation, Columbia, Maryland) to the nearest $0.1 \mathrm{~kg}$. BMI was calculated using the following formula: weight $(\mathrm{kg})$ / [height (m)]2. Secondly, percentage body fat was estimated using the BOD POD, air-displacement plethysmography (ADP) (Life Measurement, Inc, Concord, CA) device. The BOD POD is considered a reliable method of assessing body composition and has been validated through many independent research studies $(1,2,3,34,53)$. However in some subjects, 2-3 measurements were needed to obtain a satisfactory result. Prior to each test, the BOD POD was calibrated according to the manufacturer's instructions with the chamber empty and using a cylinder of known volume (49.55 L). Subjects wearing a fitted bathing suit and swimming cap, entered and sat inside the chamber. The full test required 3-5 minutes to complete and body fat percentage was automatically calculated by the computer; body density was calculated as weight/body volume and body fat percentage was calculated by using Brozek's formula (35).

The same subjects were asked to participate in two separate tests to investigate the effects of caffeine on an anaerobic power ability using Wingate anaerobic test and by $1600 \mathrm{~m}$ run for aerobic endurance test. Both tests were administered to determine the effects of consuming $160 \mathrm{mg}$ caffeine (2 Red Bull cans) and placebo drinks on the students' athletic performance.

\section{Anaerobic power measurement:}

Wingate anaerobic test:

Fourteen college students with an average age of 21.5 years old participated in a crossover study in which they were randomized to supplement with consumption of 2 cans of Red Bull (160 mg) caffeine which is equivalent approximately to $2 \mathrm{mg} / \mathrm{kg}$ of the subjects mean body weight or consumption of the noncaffeinated placebo, separated by 2 days.

On the first laboratory visit, the students performed a Wingate anaerobic test (WAnTs) after drinking 2 cans of Red Bull 60 minutes prior to the testing to determine peak power(w), peak power in (w/kg), average power (w) and average power in $(\mathrm{w} / \mathrm{kg})$. Following a minimum of 48 hours of rest, the subjects returned to the laboratory for the second testing session where a placebo was ingested sixty minutes after consumption of 2 placebo drinks (Fresca) containing a sugar-free, caffeine-free. The content of the placebo drink was placed in 2 Red Bull cans and then the subjects performed Wingate cycling tests. The reason why we asked the subjects to consume 2 drinks 2 hours prior to testing is because caffeine can be absorbed in stomach and reached the blood stream in about 45 minutes. Also, the reason why we repeated the test after 2 days was because the half-life of caffeine is 4-6 hours (44).

Three 30-s Wingate cycling tests (load $=0.075$ $\mathrm{kp} / \mathrm{kg}$ body weight), with $2 \mathrm{~min}$ of recovery between tests were used to assess peak and average power output. The anaerobic power output was determined using the Monark cycle ergometer (Monark-Crescent AB, Varberg, Sweden). Ten minutes prior to the test, each subject was instructed to perform general warmup and stretching of the quadriceps muscles 
before mounting the stationary bike. The seat height was then adjusted according to individual preference. The pedaling tension was adjusted in proportion to body weight $(4.41 \mathrm{~J} / \mathrm{rev} / \mathrm{kg}$ body weight) as the subject began pedaling slowly and evenly. When the tension was set, the subject began pedaling with maximal effort and speed, with consistent verbal encouragement provided by the examiner, for a timed $30 \mathrm{sec}$ interval. Pedal revolutions were counted and recorded during this time interval.

\section{Aerobic endurance measures:}

The effects of caffeine on subjects aerobic endurance performance was investigated by drinking 2 cans $(160 \mathrm{mg})$ of Red Bull and subject to a $1600 \mathrm{~m}(1.6 \mathrm{~km})$ aerobic endurance test in the 400 meter flat running course. The total time to complete the course is recorded for each participant in minutes and seconds using a stop watch (Accusplit Pro Survivor - A601X). All the subjects had previously performed (1.6 $\mathrm{km})$ testing on this course. On the day of the test 60 minutes prior, subjects drank 2 Red Bull cans ( $2 \mathrm{mg} / \mathrm{kg}$ body weight) followed by 10 minutes of general warm-up and stretching. A heart rate monitor (Polar FT10, Kempele, Finland) was worn to record the pulse during and at the end of the test. After 2 days, the same subjects performed the same test with consumption of 2 placebo drinks (Fresca) containing a sugar-free, caffeine-free. The content of the placebo drink was placed in 2 Red Bull cans. The volume of all drinks was $250 \mathrm{ml}$ (equivalent to a standard can of Red Bull Energy Drink). The time in minutes and seconds was recorded immediately after the completion of the test.

\section{Statistics Analysis:}

The statistical calculations were carried out using the statistical software Statistical Package for the Social Sciences (SPSS) for Windows, release 17.0 (Chicago, IL). P values less than or equal to 0.05 on two sided tests were considered statistically significant. Pre to post semester changes (pre- post) were calculated for each of the anthropometric measures obtained in the study. Two Student t-test for dependent samples was used to evaluate the statistical significance of each group using Red Bull and a placebo for aerobic and anaerobic tests.

\section{Results:}

The results of the present study showed a statistically significant difference in body composition (BMI and \%body fat), anaerobic ability and no differences in aerobic ability in subjects consuming Red Bull daily.

Table (1)

Subject descriptive data for 84 college male students who completed the questionnaire

\begin{tabular}{|c|c|c|c|c|}
\hline Variables & Minimum & Maximum & Mean & Std. Deviation \\
\hline Age (y) & 19.0 & 21.3 & 20.0 & .79 \\
\hline Body Weight $(\mathrm{kg})$ & 72.9 & 83.6 & 79.8 & 2.95 \\
\hline Body Height $(\mathrm{cm})$ & 158.5 & 173.2 & 166.1 & 4.26 \\
\hline BMI & 16.0 & 26.8 & 22.5 & 1.94 \\
\hline \%BF & 14.0 & 16.3 & 15.0 & .75 \\
\hline
\end{tabular}

Values Represent Means \pm SEM

Abbreviation: $B M I=$ Body Weight Index, \%BF =Percent Body Fat

Table 1 shows a mean body weight of $79.8 \mathrm{~kg}$, body height of $166.1 \mathrm{~cm}$, BMI of 22.5 and percent body fat of $15.0 \%$ in 84 college males students who completed the questionnaire. 
Table (2)

The frequencies of Red Bull consumption among 84 college students

\begin{tabular}{|c|c|c|}
\hline \multirow[t]{2}{*}{ Red Bull (Can/week) } & \multicolumn{2}{|c|}{$\begin{array}{c}\text { Number }(\mathrm{N}) \text { and } \\
\text { Percentage }(\%)\end{array}$} \\
\hline & $\mathrm{N}$ & $\%$ \\
\hline Every day (7days) & 14 & 16.7 \\
\hline $5-6$ & 10 & 11.9 \\
\hline $4-5$ & 8 & 9.5 \\
\hline $3-4$ & 11 & 13.1 \\
\hline $2-3$ & 16 & 19.0 \\
\hline $1-2$ & 20 & 23.8 \\
\hline non & 5 & 6.0 \\
\hline Total & 84 & 100 \\
\hline
\end{tabular}

Table 2 shows the results out of total 285 Red Bull daily 20 (23.8\%) students consumed students who enrolled in the 2011 semester, Red Bull drinks once or twice a week. Only 5 only $84(29.5 \%)$ completed the questionnaire. (6\%) students reported that they do not drink Out of 84 students only $14(16.7 \%)$ consumed any energy drinks.

Table (3)

Results and responses of knowledge and reasons questionnaire's by the college students who consumed energy drink (Red Bull) in the first 2011 semester $(N=79)$

\begin{tabular}{|l|c|}
\hline \multicolumn{1}{|c|}{ Variables } & No (percentages) \\
\hline Consuming Energy Drink & $79(100 \%)$ \\
\hline Consuming Energy Drinks (Red Bull) Daily & $14(17.7 \%)$ \\
\hline Contains Caffeine & $8(4.8 \%)$ \\
\hline Negative Side Effects & $42(50.0 \%)$ \\
\hline Positive Effects & $75(89.2 \%)$ \\
\hline Cause Headache & $13(15.5 \%)$ \\
\hline Cause Alertness & $53(63.1 \%)$ \\
\hline Cause Heart Palpitations & $6(7.1 \%)$ \\
\hline Insufficient Sleep & $18(21.4 \%)$ \\
\hline Energy Increases Physical Fitness & $77(91.7 \%)$ \\
\hline Weight Gain & $36(42.9 \%)$ \\
\hline Difference Between Energy and Sports Drinks & $7(8.3 \%)$ \\
\hline
\end{tabular}

Table 3 shows the knowledge of the 79 students (since 5 from 84 students who responded to the questionnaire did not consume energy drinks) whom consumed energy drinks. $8(4.8 \%)$ were aware of the caffeine content in energy drinks, $42(50.0 \%), 75(89.2 \%)$ were aware of the negative or positive side effects respectively. Only13 (54\%) students reported having headaches, 53 (63.1\%) reported causing alertness, $6(7.1 \%)$ knew that it can cause heart palpitations and $18(21.4 \%)$ believed consuming energy drinks caused insufficient sleep. The majority of students consuming energy drinks to increase energy level (physical fitness) 77 $(91.7 \%)$, only $36(42.9 \%)$ believed that consuming Red Bull can increase body weight. Only 7 students (8.3\%) were able to differentiate between sport and energy drinks.

Table (4)

Subject descriptive data for 14 college male students who consumed Red Bull daily in the present study

\begin{tabular}{|c|c|c|c|c|}
\hline Variables & Minimum & Maximum & Mean & Std. Deviation \\
\hline Age $(\mathrm{y})$ & 19.0 & 21.3 & 20.1 & .84 \\
\hline Body Weight $(\mathrm{kg})$ & 68.9 & 72.4 & 70.4 & 1.17 \\
\hline Body Height $(\mathrm{cm})$ & 158.5 & 170.0 & 166.3 & 3.50 \\
\hline BMI & 24.0 & 27.7 & 25.6 & 1.07 \\
\hline \%BF & 16.9 & 18.6 & 17.3 & .43 \\
\hline
\end{tabular}

Table 4 illustrates the information of the $14 \pm 1.17 \mathrm{~kg}$, height $166.3 \pm 3.5 \mathrm{~cm}$, BMI 25.6 students who consumed a Red Bull drink daily. $\quad \pm 1.07(\mathrm{~kg}) /$ height $(\mathrm{m})] 2$ and \%BF $17.3 \pm .43$ Their mean \pm SD of body weight was 70.4 respectively. 
Table (5)

Body composition changes of 14 college male students who consumed Red Bull daily at the beginning and at the end of the 2011 semester (3 month period)

\begin{tabular}{|c|c|c|c|}
\hline Body Composition & At the beginning semester & At the end semester & P value \\
\hline Age $(\mathrm{yrs})$ & 20.3 & 20.6 & $0.00^{*}$ \\
\hline Body Weight $(\mathrm{kg})$ & $70.4 \pm 1.17$ & $73.1 \pm 1.14$ & $0.00^{*}$ \\
\hline Body Height $(\mathrm{cm})$ & $166.3 \pm 3.5$ & $166.5 \pm 3.3$ & 0.90 \\
\hline BMI & $23.0 \pm 2.06$ & $26.5 \pm 1.07$ & $0.03^{*}$ \\
\hline$\%$ body fat & $17.3 \pm .43$ & $18.1 \pm .27$ & $0.01^{*}$ \\
\hline
\end{tabular}

$*(P \leq 0.05)$ indicates significant differences in age and body composition between students at the beginning and at the end semester

Abbreviation: $B M I=$ Body Weight Index, \%BF =Percent Body Fat

The results in Table 5 illustrates significant differences $(\mathrm{P} \leq 0.05)$ in age, body weight, BMI and \%body fat from the beginning of semester and at the end of the same semester in 14 college males students who consumed Red Bull daily.

Table (6)

Physiological responses to Wingate test with Red Bull and Placebo consumption

\begin{tabular}{|c|c|c|c|c|}
\hline Variables & Rest & $\begin{array}{c}\text { After Consuming 2 Red Bull } \\
\text { Cans (160 mg) Caffeine }\end{array}$ & Placebo & P value \\
\hline Mean HR (bpm) & $77.9 \pm 1.9$ & $186.0 \pm .15$ & $185.2 \pm .11$ & $0.02^{*}$ \\
\hline Mean SBP (mmHg) & $76.7 \pm .86$ & $77.3 \pm .69$ & $76.3 \pm .66$ & $0.01^{*}$ \\
\hline Mean DBP (mmHg) & $121.9 \pm .75$ & $122.2 \pm .79$ & $120.8 \pm .75$ & $0.01^{*}$ \\
& & & & \\
\hline Peak Power (w) & - & $720.11 \pm 150.0$ & $688.44 \pm 157.7$ & $0.006^{*}$ \\
\hline Peak Power $(\mathrm{w} / \mathrm{kg})$ & - & $10.4 \pm 1.4$ & $9.9 \pm 1.2$ & $0.003^{*}$ \\
\hline Average Power $(\mathrm{w})$ & - & $575.22 \pm 95.9$ & $542.9 \pm 101.1$ & $0.002^{*}$ \\
\hline Average Power $(\mathrm{w} / \mathrm{kg})$ & - & $8.3 \pm 1.1$ & $7.8 \pm .95$ & $0.002^{*}$ \\
\hline
\end{tabular}

$*(P \leq 0.05)$ significant differences

Abbreviation: Mean HR $($ bpm $)=$ mean heart rate per minute, Mean $\mathrm{SBP}(\mathrm{mmHg})=$ mean systolic blood pressure (millimeters of mercury), Mean DBP $(\mathrm{mmHg})=$ mean diastolic blood pressure (millimeters of mercury), $w=$ watts

Table 6 shows an increase in heart rate, mean DBP $(\mathrm{mmHg})$, mean SBP $(\mathrm{mmHg})$, peak power (w), peak power (w/kg), average power (w) and average power $(\mathrm{w} / \mathrm{kg})$ when subjects consumed a Red Bull, respectively. A t-test also showed significant differences $(\mathrm{P} \leq 0.05)$ after consuming 2 cans of Red Bull comparing with placebo for all Wingate variables.

Table (7)

The effects of Red Bull drink consumption on aerobic performance with the $1600 \mathrm{~m}$ run test

\begin{tabular}{|c|c|c|c|c|}
\hline Variables & $\begin{array}{r}\mathrm{R} \\
\text { est }\end{array}$ & $\begin{array}{c}\text { After Consuming 2 Red Bull } \\
\text { Cans }(160 \mathrm{mg}) \text { Caffeine }\end{array}$ & Placebo & P value \\
\hline Pre-test HR $(\mathrm{bpm})$ & $75.9 \pm 1.9$ & $76.3 \pm .82$ & $75.6 \pm 1.02$ & .055 \\
\hline Pro-test HR $(\mathrm{bpm})$ & - & $185.5 \pm .67$ & $185.5 \pm .49$ & .932 \\
\hline Mean SBP $(\mathrm{mmHg})$ & $76.1 \pm .76$ & $77.0 \pm .86$ & $76.3 \pm .66$ & $.031^{*}$ \\
\hline Mean DBP $(\mathrm{mmHg})$ & $119.7 \pm 3.2$ & $121.5 \pm 1.20$ & $120.5 \pm 1.09$ & $.042^{*}$ \\
\hline Test Time $(\mathrm{min} / \mathrm{s})$ & - & $13.36 \pm .07$ & $13.37 \pm .08$ & .914 \\
\hline
\end{tabular}

$*(P \leq 0.05)$ significant differences

Abbreviation: HR $($ bpm $)=$ Heart rate Beats/min, $($ DBP $)$ Diastolic blood Pressure, $($ SBP $)$ Systolic blood pressure

Table 7 shows significant differences $(\mathrm{P} \leq 0.05)$ in mean SBP (.031) and DBP (mmHg) (.042) for the 1600 meter run test between Red Bull drink consumption and the placebo 1 hour prior to the test on aerobic performance among college students. There are no significant differences $(\mathrm{P} \leq 0.05)$ in both groups for pre and pro-heart rate and time to complete the test. 


\section{Discussion:}

Energy drink consumption is a popular practice among college students for a variety of reasons. In the present study, 59 (96.7\%) of 84 Kuwaiti students surveyed were regular consumers of energy drinks (Red Bull) with 14 (16.7\%) daily consumers. The major reason for consuming energy drinks was to increase the energy level and to improve physical performance.

Sports and energy drink consumption have increased in popularity among adolescent students, especially college students. However, concerns have been raised regarding the ingredients in energy drinks and their potential negative effects on health. Also, an increase in percent body fat was reported which may have contributed to the problems associated with student health.

A study conducted by Malinauskas et al. (14) surveyed energy drink consumption among 496 college students in the United States and found that $51 \%$ reported drinking at least one energy drink each month in the past semester. Also, Woolsey et al. (17) reported that $48 \%$ of intercollegiate student athletes used energy drinks. A study conducted by Oteri et al. (18) surveyed 450 students at the School of Medicine at the University of Messina. Their study found that $56.9 \%$ of those surveyed reported using energy drinks. Attila and Cakir (19) reported that consumption of energy drinks is quite common among 439 (48.3\%) college students from Hacettepe University (Ankara, Turkey). Also from Turkey, Arpaci et al. (50) studied a total of 153 students (65 females, 88 males) from three physical education and sport departments at different universities in Ankara and reported that the consumption frequencies of sports drinks were never (34\%), twice a week $(20 \%)$,once per week $(18 \%)$, every other day (12\%) and every day (12\%). Energy drink consumption were reported as never $(37.1 \%)$, once per week $(24.2 \%)$, twice a week $(14.5 \%)$, every other day (8.1\%) and every day (4.8\%). A study conducted by O'Dea (24) reported that among 78 adolescent children, aged 11-18 years from a co-educational government high school, $56.4 \%$ consumed sports drinks, and $42.3 \%$ consumed energy drinks. One hundred thirty seven students from the physical education department in Argentina consumed energy drinks 20 times or more in the last month (31). Tian et al. (32) reported that in competition season, students 18 years or older enrolled in the University in Singapore consumed 2.8 Red Bull drinks per week and one drink per week in the off season. Arpaci et al. (50) reported that $43.1 \%$ of participants had known the difference between sports and energy drinks. But only $15 \%$ of participants reported to have knowledge of the ingredients of sports drink, and only $9.2 \%$ of participants knew the ingredients of energy drinks.

Although energy drinks are targeted to young adult consumers, there has been little research regarding energy drink consumption patterns among college students in the State of Kuwait.

Results of current study showed that some of the college students could not differentiate between sports and energy drinks $(8.3 \%)$ and also do not know the ingredients of them especially caffeine (4.8\%). The students believed there are more positive effects $(89.2 \%)$ than negative effects of consuming caffeine (50\%). Moreover, side effects from consuming energy drinks are quite common and students should improve their knowledge regarding the positive and negative side effect associated with high quantity caffeine consumption from Red Bull. The college students should recognize the amounts of caffeine that are present in the wide variety of caffeine-containing products especially Red Bull. Availability of this information may reduce the Red Bull or energy drinks consumption among college students. Since fluid such as water and sports drinks which contain minerals and low carbohydrates are important for sports performance, the athletes and students of physical education and sport should replace the Red Bull with these drinks.

\section{Caffeine side effects:}

Clauson et al. (10) reported that caffeine and sugar in Red Bull are present in amounts known to cause a variety of adverse health effects such as insomnia, nervousness, headache, and tachycardia. Malinauskas (14) indicated that the top reasons for using energy drinks were insufficient sleep, low energy levels and to extend studying time. Also, 29\% of users experienced minor shock, with $22 \%$ reporting 
headaches and $19 \%$ reporting heart palpitations from consuming energy drinks. Most studies reported an association between use of alcohol and energy drinks (55). Due to the Islamic influence in Kuwait society, there is no ground for this problem.

Kaminer (58) reported that students consume Red Bull to improve physical and cognitive performance such as concentration, attention, and alertness. Ballistreri et al. (31) reported that $13.9 \%$ of the Physical Education students believed that consuming Red Bull improves sport performance. Also, out 140 triathlon athletes (105 men and 35 women) representing 16 countries, $73 \%$ believed that caffeine improved their endurance ability (62).

In the present study, $91.7 \%$ of the students believed that consuming Red Bull will increase energy level to meet the physical demands of the department's practical courses. However, $15.5 \%, 63.1 \%$ and $7.1 \%$ reported that they experienced headache, alertness and heart palpitations, respectively.

It seems that the main reason to consume Red Bull by students was to increase energy levels to meet physical fitness class requirements as part of department's curriculum.

\section{Aerobic effects:}

Conflicting results from many studies concluded that caffeine can improve performance in both short and long term endurance events as well as short term high intensity intermittent exercises.

The manufacturing company claimed that caffeine can prolonged exercise by increasing the ability to facilitate the release of free-fatty acids into blood stream preserving muscle glycogen during exercise $(7,8)$.

The majority of studies found that caffeine consumption, at intakes of 2.5 to $6 \mathrm{mg}$ per $\mathrm{kg}$ bodyweight, enhanced physical performance (33, 34, 35 ). Ganio et al. (20) reported that caffeine is an ergogenic aid for endurance athletes when taken before and/or during exercise in moderate quantities (3-6 mg. kg body weight). Also, Bell and McLellan (38) used $2.5,5 \mathrm{mg} / \mathrm{kg}$ of caffeine to investigate the time to exhaustion in 9 male cyclists' which reported an increase in endurance ability after both doses of caffeine. Also using cyclists as subjects, Jenkins et al. (52) concluded that caffeine preparations of 2 and $3 \mathrm{mg} / \mathrm{kg}$ enhanced performance.

A study conducted by Ivy et al. (6) investigated 6 male and 6 female trained cyclists who consumed $500 \mathrm{ml}$ of either flavored placebo or Red Bull Energy Drink $40 \mathrm{~min}$ before a simulated cycling time trial. They reported an improved performance with Red Bull drink compared with placebo. Also, Bridge and Jones (35) investigated $3 \mathrm{mg} / \mathrm{kg}-1$ of caffeine or placebo ingestion based on body weight for eight male long-distance runners and they reported an improvement on an $8 \mathrm{~km}$ run performance with caffeine. Doherty and Smith $(41,42)$ in two separate studies examined evidence from 40 double-blind studies on exercise performance using two meta-analyses and reported that caffeine improved exercise test performance by $12 \%$ and that the effect was more pronounced for endurance exercise than for graded or short-term exercise where caffeine ingestion accounted for $30 \%$ of the improvement in exercise performance.

In contrast, Malek et al. (36) gave 34 students 1 dose ( 3 pills $=201 \mathrm{mg}$ of caffeine) daily for 8 weeks and Hunter et al. (37) gave 8 trained cyclists $6 \mathrm{mg}$ per $\mathrm{kg}$ bodyweight per day and found no effects. Also, Desbrow et al. (48) found that 1.5 or $3 \mathrm{mg}$ doses per $\mathrm{kg}$ of body weight of caffeine had failed to improve endurance performance in whom consumed caffeine and trained subjects. In the Tarnopolsky (49) investigation, caffeine consumed at 2-6 mg/kg before exercise or 0.75 $2.0 \mathrm{mg} / \mathrm{kg}$ during exercise enhanced endurance performance but not high-intensity sprint or strength performance. Nienhueser et al. (60) studied ten healthy males who consumed $473 \mathrm{ml}$ of one of three commercially available energy drinks or a placebo and then resting metabolic rate (RMR) and Respiratory Exchange Ratio (RER) were measured 1 hour later. They found no effects on submaximal endurance exercise.

In the present study there were significant differences $(\mathrm{P} \leq 0.05)$ in mean SBP $\mathrm{mmHg}$ and DBP mmHg for the 1600 meter run test between Red Bull drink consumption and placebo 1 hour prior to the test on aerobic performance among college students. These differences were due to the effect of caffeine consumption in 
cardiovascular function $(9,10,41,56)$. However, the caffeine did not affect the time to complete the test which was an indication that 2 cans of Red Bull drink (160 mg of caffeine which is equivalent approximately to $2 \mathrm{mg} / \mathrm{kg}$ of all subjects mean body weight) did not enhance the aerobic ability of students performance in comparison to non-caffeinated placebo. In addition, the effects of energy drink ingredients on physical and cognitive performances remain controversial.

\section{Anaerobic effects:}

Davis and Green (21) explained the role of caffeine in speed endurance. They also reported that caffeine had minimal effects on performance during a 30 second Wingate test. Conversely, several studies $(23,40,46,47)$ have shown that caffeine has ergogenic effects during high-intensity intermittent exercise. Glaister et al. (45) studied the effects of caffeine supplementation on multiple sprinting running performances. They concluded that caffeine has ergogenic properties with the potential to benefit performance in both single and multiple sprint sports. In two different studies, Scholey and Kennedy $(56,57)$ supported the energy drink manufacturer claims that the drinks increased performance, endurance, concentration, reaction time, and enhanced mood. Sunderland et al. (61) reported that caffeine improved repeated anaerobic performance when measured by a Wingate and sprint test and concluded that caffeine should be considered a possible ergogenic aid for short duration, very highintensity performance.

On the contrary, Paton et al (22) suggested that caffeine dose not enhance sprint performance. Collomp et al. (43) studied the effects of caffeine ingestion on the Wingate anaerobic test performance using six healthy volunteers and reported no improvement in physical performance. Greer et al. (44) reported that there was no indication of increased anaerobic metabolism after caffeine ingestion using Wingate test. Woolf et al. (53) selected 17 Collegiate football athletes who ingested a caffeinated $(5 \mathrm{mg} / \mathrm{kg}$ BW caffeine and placebo $(0.125 \mathrm{~g} / \mathrm{kg}$ body weight carbohydrate) beverage. They reported that caffeine did not improve performance for anaerobic exercise tests used at the NFL. Forbes et al. (54) indicated in their study that Red Bull energy drinks significantly increased upper body muscle endurance but had no effect on anaerobic peak or average power during repeated Wingate cycling tests in young healthy adults. Mueller et al. (55) also tested if Red Bull or the placebo affected performance. They recruited college students who were given either Red Bull or a placebo drink 15 min before the 30s Wingate test. They concluded that effect of Red Bull on the performance was insignificant. Crowe et al. (59) reported that consuming 6 $\mathrm{mg} / \mathrm{kg}$ of body weight of caffeine had no significant effect on peak power, work output, RPE, or peak heart rate.

Hogervorst et al. (5) recruited twenty four welltrained cyclists who consumed $45 \mathrm{~g}$ of carbohydrate, $100 \mathrm{mg}$ of caffeine or $300 \mathrm{~mL}$ of placebo beverage immediately before performing a 2.5 -h exercise at $60 \%$ VO2max. The results showed that participants were significantly faster after caffeine consumption when compared with carbohydrate and the placebo beverage.

Ruxton in 2008 (39) reviewed all double-blind, placebo-controlled studies published over the past 15 years and concluded that the range of caffeine intake that could maximize benefit and minimize risk in relation to mood, cognitive function, and physical performance is 38 to 400 mg per day.

Currently in our study, the subjects consumed 2 Red Bull drinks containing $160 \mathrm{mg}$ of caffeine or placebo pre and post Wingate test. The results indicated an improvement on all Wingate test variables after Red Bull drinks consumption in comparison with placebo. Therefore, we can conclude that caffeine positively affected muscular strength and endurance.

\section{Body composition effects:}

There is conflicting evidence regarding the impact of energy drinks on body composition. Due to the amount of sugar (Sucrose, Glucose) contained in a can of Red Bull, weight gain can be an unhealthy side effect with high consumption. Since the Red Bull energy drink has 54 grams of sugar per 236 milliliter, a can of Red Bull has 220 calories $(16,51)$.

Most energy drinks make the claim that they stimulate metabolism and as a result, promoting 
weight loss (13). Some studies have shown that excessive Red Bull drinking is associated with weight gain $(26,29)$ where others reported that it has no effects (36). Malinauskas et al. (14) suggested further investigation should focus on a college students' knowledge of the amount of caffeine in a can and its side effects.

The authors measured the weight and the height of the subjects to calculate the BMI and percent body fat and then compare the results from the beginning of the semester to the end ( 3 months periods).

According to the results of the survey conducted in present study on physical education department students, a high number of students who consumed Red Bull believed that Red Bull caused weight gain (42.9\%). There were statistically significant differences in percent body fat of the 14 students whom consumed Red Bull daily from the beginning of semester $17.3 \pm .43$ and at the end of the same semester $18.1 \pm .27$ which may be the result of Red Bull consumption. Since we did not control dietary habits or exercise habits, the weight gain may have not been as the result of daily Red Bull consumption.

\section{Conclusions:}

The results of this study indicated that out of 84 male students from the Department of Physical Education and Sport attending the College of Basic Education in Public Authority of Applied Education and Training in The State of Kuwait surveyed, only $14(17.7 \%)$ consumed Red Bull daily. The majority of the students believed Red Bull drinks increased energy (physical fitness), only 7 students $(8.3 \%)$ could differentiate between energy and sports drinks and had no knowledge that Red Bull contains caffeine.

In addition, consuming 2 cans of the commercially available energy drink (Red Bull) which contains $160 \mathrm{mg}$ of caffeine, equivalent approximately to $2 \mathrm{mg} / \mathrm{kg}$ body weight, significantly enhanced the anaerobic performance (Wingate test) of the student but had no effects on aerobic ability (1600 meter run) of physical education college students.

Awareness of college students of the ingredients and potential health hazards of energy drinks
(Red Bull) should be emphasized in college curriculum through nutritional and health education classes.

\section{References:}

1. Froiland K, Koszewski W, Hingst J, Kopecky L. Nutritional supplement use among college athletes and their sources of information. Int $\mathbf{J}$ Sports Nutri Exerc Metab. 2004 Feb;14(1):104120.

2. Hoffman JR, Faigenbaum AD, Ratamess NA, Ross R, Kang J Tenenbaum G. Nutritional supplementation and anabolic steroid use in adolescents. Med Sci Sports Exerc. 2008 Jan;40(1):15-24.

3. Desbrow B, Leveritt M. Awareness and use of caffeine by athletes competing at the 2005 Ironman Triathlon World Championships. Int $\mathbf{J}$ Sports Nutri Exerc Metab. 2006 Oct; 16(5):545558.

4. Petroczi A, Naughton DP, Pearce G, Baily R, Bloodworth A, McNamee M. Nutritional supplement use by elite young UK athletes: fallacies of advice regarding efficacy.J Int Soc Sports Nutr. 2008 Dec 15; 5:22.

5. Hogervorst E, Banddelow S, Schmitt J, Jentjens R, Oliveira M, Allgrove J, Carter T. Caffeine improves physical and cognitive performance during exhaustive exercise. Med Sci Sports Exerc. 2008 Oct; 40(10):1841-1851.

6. Ivy Jl, Kammer L, Ding Z, Wang B, Bernard JR, Liao YH, Hwang J. Improved cycling timetrial performance after ingestion of a caffeine energy drink. Int J Sports Nutri Exerc Metab. 2009 Feb; 19(1):61-78.

7. Powers SK, Dodd S. Caffeine and endurance performance. Sports Med. 1985 May-Jun; 2(3):165-174.

8. Davis JK, Green JM. Caffeine and anaerobic performance: ergogenic value and mechanisms of action. Sports Med. 2009; 39(10):813-832.

9. Rahnama N, Gaeini AA, Kazemi F. The effectiveness of two energy drinks on selected indices of maximal cardiorespiratory fitness and blood lactate levels in male athletes. J Res Med Sci. 2010 May; 15(3):127-132. 
10. Clauson K, Shields K, McQueen C, Persad N. Safety issues associated with commercially available energy drinks. J Am Pharm Assoc. 2008; 48(3):e55-e63.

11. Baum M, Weiss $M$. The influence of a taurine containing drink on cardiac parameters before and after exercise measured by echocardiography. Amino Acids. 2001; 20(1):75-82.

12. Bichler A, Swenson A, Harris MA. A combination of caffeine and taurine had no effect on short term memory but induces changes in heart rate and mean arterial blood pressure. Amino Acids. 2006 May; 31(4):471476.

13. Ballard SL, Jennifer J. Wellborn-Kim, and Kevin A. Effects of Commercial Energy Drink Consumption on Athletic Performance and Body Composition. The physician and sports medicine, 28(1):107-117, 2010.

14. Malinauskas BM, Aeby VG, Overton RF, Carpenter-Aeby T, Barber-Heidal K. A survey of energy drinks consumption patterns among college students. Nutr J. 2007; 6:35.

15. Pennington N, Johnson M, Delaney E, Blankenship MB. Energy Drinks. A New Health Hazard for Adolescents. The Journal of School Nursing. October 201026 (5): 352-359.

16. Reissig C, Strain E, Griffiths R. Caffeinated energy drinks-A growing problem. Drug \& Alcohol Dependence. 2009; 99: 1-10.

17. Woolsey C, Waigandt A and Beck N. Athletes and Energy Drinks: Reported RiskTaking and Consequences from the Combined Use of Alcohol and Energy Drinks. J Appl Sport Psych. 22(1): 65-71, 2010

18. Oteri A, Salvo F, Caputi AP, Calapai G. Intake of energy drinks in association with alcoholic beverages in a cohort of students of the School of Medicine of the University of Messina. Alcohol Clin Exp Res. 2007 Oct; 31(10):1677-1680.

19. Attila S, Cakir B. Energy-drink consumption in college students and associated factors. Nutrition. Mar 2011; 27(3):316-322.

20. Ganio MS, Klau JF, Casa DJ, Armstrong LE, Maresh CM. Effect of caffeine on sport specific endurance performance: a systematic review. J Strength Cond Res. Jan 2009; 23(1):315-324.

21. Davis JK, Green JM. Caffeine and anaerobic performance: ergogenic value and mechanisms of action. Sports Med. 2009; 39(10):813-832.

22. Paton CD, Hopkins WG, Vollebregt LL. Effect of caffeine ingestion on repeated sprints in team-sport athletes. Med Sci Sports Exerc. 2001 May; 33(5):822-825.

23. Beck TW, Housh TJ, Schmidt RJ, Johnson GO, Housh DJ, Coburn JW, Malek MH. The acute effects of a caffeine-containing supplement on strength, muscular, endurance and anaerobic capabilities. J Strength Cond Res. 2006; 20(3): 506-510.

24. O'Dea JA. Consumption of nutritional supplements among adolescents: usage and perceived benefits. Health Educ. Res. 2003;18(1):98-107.

25. Astorino TA and Roberson DW. Efficacy of acute caffeine ingestion for short-term highintensity exercise performance: A systematic review. J Strength Cond Res. 2010; 24(1):257265.

26. Rush E, Schulz S, Obolonkin V, Simmons D, Plank L. Are energy drinks contributing to the obesity epidemic? Asia Pacific Journal of Clinical Nutrition. 2006; 15(2):242-244.

27. George J, Vehrs P, Allsen P, Fellingham G and Fisher G. VO2max estimation from a submaximal 1-mile track jog for fit college-age individuals. Med Sci Sports Exerc. 1993; 25 (3):401-406.

28. Goldstein R, Ziegenfuss T, Kalman D, Kreider R, Campbell B, Wilborn C, Taylor L, Willoughby D, Stout J, Sue Graves B, Wildman R, Ivy J, Spano M, Smith A, Antonio J..International society of sports nutrition position stand: caffeine and performance. J Int Soc Sports Nutr. 2010, 7: 5.

29. Bray GA, Neilsen SJ, Popkin BM. Consumption of high-fructose corn syrup in beverages may play a role in the epidemic of obesity. Am J Clin Nutr. 2004;79:537-43.

30. Burke LM. Caffeine and sports performance. Appl Physiol Nutr Metab. 2008 Dec; 33(6):1319-1334. 
31. Ballistreri MC, Corradi-Webster CM. Consumption of energy drinks among physical education students. Rev Latino-am Enfermagem.2008; 16:558-564.

32. Tian H H, Ong W S, Tan C L. Nutritional supplement use among university athletes in Singapore. Singapore Med J. 2009; 50(2):165.

33. Norager CB, Jensen MB, Madsen MR. Caffeine improves endurance in 75-yr-old citizens: a randomized, double-blind, placebocontrolled, crossover study. J Applied Physio.2005; 99:2302-306.

34. Bell DG, McLellan TM. Exercise endurance 1,3 , and $6 \mathrm{~h}$ after caffeine ingestion in caffeine users and nonusers. J Applied Physio.2002; 93:1227-1234.

35. Bridge CA and Jones MA. The effect of caffeine ingestion on $8 \mathrm{~km}$ run performance in a field setting. J Sports Sci.2006; 24: 433-439.

36. Malek MH, Housh TJ, Coburn JW. Effects of eight weeks of caffeine supplementation and endurance training on aerobic fitness and body composition. J Strength Cond Res. 2006; 20: 751-755.

37. Hunter AM, St Clair Gibson A, Collins M. Caffeine ingestion does not alter performance during a $100-\mathrm{km}$ cycling time-trial performance. Int J Sports Nutr Exerc Metab. 2002; 12:438452.

38. Bell DG and McLellan TM. Effect of repeated caffeine ingestion on repeated exhaustive exercise endurance. Med Sci Sports Exerc. 2003; 35:1348-1354.

39. Ruxton $\mathrm{CH}$. The impact of caffeine on mood, cognitive function, performance and hydration: a review of benefits and risks. Nutrition Bulletin. 2008; 33(1):15-25.

40. Wiles JD, Coleman D, Tegerdine M. The effects of caffeine ingestion on performance time, speed and power during a laboratorybased $1 \mathrm{~km}$ cycling time-trial. J Sports Sci. 2006; 24:1165-1171.

41. Doherty $M$ and Smith PM. Effects of caffeine ingestion on exercise testing: a metaanalysis. Int J Sports Nutr Exere Metab. 2004; 14: 626-646.

42. Doherty, M. and Smith, P.M. Effects of caffeine ingestion on rating of perceived exertion during and after exercise: a metaanalysis. Scandinavian J Medicine and Science in Sports, 2005; 15, 69-78.

43. Collomp K, Ahmaidi S, Audran M, Chanal JL, Prefaut C: Effects of caffeine ingestion on performance and anaerobic metabolism during the Wingate test. Int J of Sports Med 1991, 12:439-43.

44. Greer F, McLean C, Graham TE. Caffeine, performance, and metabolism during repeated Wingate exercise tests. J Appl Physiol. 1998 Oct; 85(4):1502-1508.

45. Glaister M, Howaston G, Abraham CS, Lockey RA, Goodwin JE, Foley P, Mc Innes G. Caffeine supplementation and multiple sprint running performance. Med Sci Sports Exerc. 2008 Oct; 40(10):1835-1840.

46. Carr A, Dawson B, Schneiker K, Goodman C, Lay B. Effect of caffeine supplementation on repeated sprint running performance. J sports Med Phys Fitness. 2008 Dec; 48(4):472-478.

47. Schneiker Kt, Bishop D, Dawson B, Hackett LP. Effects of caffeine on prolonged intermittent sprint ability in team-sport athletes. . Med Sci Sports Exerc. 2006 Mar; 38(3):578585.

48. Desbrow B, Barrett CM, Minahan CL, Grant GD, Leveritt MD. Caffeine, cycling performance, and exogenous $\mathrm{CHO}$ oxidation: a dose-response study. Med Sci Sports Exerc. 2009 Sep; 41(9):1744-1751.

49. Tarnopolsky M. Caffeine and Creatine Use in Sport. Ann Nutr Metab. 2010; 57(suppl 2):18.

50. Arpaci N, Tosun S, Ersoy G. Sports and energy drink consumption of physical education and sports students' their knowledge about them. Movement and Health, Issue 2 suppl. 2010.

51. Higgins JP, Tuttle TD, Higgins CL. Energy Beverages: Content and Safety. Mayo Clin Proc. November 2010; 85(11):1033-1041.

52. Jenkins NT, Trilk JL, Singhal A, O'Connor KJ. Ergogenic effects of low doses of caffeine on cycling performance. Int J Sports Nutr Exere Metab. 2008; Jun; 18(3):328-342.

53. Woolf K, Bidwell WK, Carlson AG. Effect of caffeine as an ergogenic aid during anaerobic exercise performance in caffeine naive 
collegiate football players. J Strength Cond Res. 2009 Aug; 23(5):1363-1369.

54. Forbes SC, Darren G Candow, Jonathan P Little, Charlene Magnus, Philip D Chilibeck. Effect of Red Bull energy drink on repeated Wingate cycle performance and bench-press muscle endurance. Int $\mathrm{J}$ Sport Nutr Exerc Metab. 2007; 17(5):433-444.

55. Mueller EL, Weise MM, Rado LC, Cass TJ. Effects of Red Bull on Wingate Testing of College Aged Students. Journal of Undergraduate Kinesiology Research. May 2007; 2(2):12-18.

56. Scholey AB, Kennedy DO. Cognitive and physiological effects of an "energy drink": An evaluation of the whole energy drink and of glucose, caffeine and herbal flavoring fractions. Psychopharmacology. 2004; 176:320-330.

57. Scholey AB and Kennedy DO. A glucosecaffeine 'energy drink' ameliorates subjective and performance deficits during prolonged cognitive demand. Appetite. 2004; 42:331-333.
58. Kaminer Y. Problematic use of energy drinks by adolescents. Child Adolesc Psychiatr Clin N Am. 2010 Jul; 19(3):643-650.

59. Rowe $\mathrm{Mj}$, Leicht AS, Spinks WL. Physiological and cognitive responses to caffeine during repeated, high intensity exercise. Int J Sport Nutr Exerc Metab. 2006 Oct; 16(5):528-544.

60. Nienhueser J, Brown G, Shaw B, and ShawI. Effects of energy drinks on metabolism at rest and during submaximal treadmill exercise in college age males. Int J Exerc Sci. 2011; 4(1):65-76.

61. Sunderland, K; Greer, F; Torok, Z. Multiple Sprint Performance and Wingate Measures Following Acute Caffeine Ingestion. J Strength Cond Res. March 2011; 25, supp 1.

62. Desbbrow B, Leveritt M. Well trained endurance athletes' knowledge, insight, and experience of caffeine use. Int $\mathbf{J}$ Sport Nutr Exerc Metab. 2007 Aug; 17(4):328-339. 